\title{
OS MEIOS CONSENSUAIS PARA ADMINISTRAÇÃO DE CONFLITOS NAS RELAÇÕES INTERNACIONAIS
}

\author{
THE CONSENSUAL MEANS FOR DISPUTES SETTLEMENT IN \\ INTERNATIONAL RELATIONS
}

\author{
Ricardo Soares Stersi dos Santos ${ }^{1}$
}

\section{RESUMO}

As formas de relações internacionais mais comuns são os conflitos e as cooperações entre os atores internacionais. Para a gestão dos conflitos internacionais são utilizados frequentemente os métodos pacíficos e consensuais como: negociação diplomática; mediação; conciliação; bons ofícios; comissão de investigação; conferência; congresso. Os meios consensuais ou diplomáticos destacam a manifestação de vontade dos atores internacionais, a busca pela satisfação dos interesses nacionais e a celebração do acordo como os elementos importantes na gestão dos conflitos internacionais.

Palavras-chave: Conflitos internacionais; Cooperação internacional; Métodos consensuais; Relações internacionais.

\begin{abstract}
The most usual forms of international relations are conflicts and cooperation between international actors. For the settlement of international disputes, peaceful and consensual methods are frequently used such as diplomatic negotiation; mediation; conciliation; good offices; commission of inquiry; conference; congress. The consensual or diplomatic means highlight the manifestation of the will of the international actors, the pursuit of the satisfaction of national interests and the conclusion of the agreement as the important elements in the settlement of international disputes.
\end{abstract}

Keywords: International disputes; International cooperation; Consensual methods; International relations.

\footnotetext{
${ }^{1}$ Professor dos Cursos de Graduação e de Pós-Graduação em Direito da Universidade Federal de Santa Catarina - UFSC, Florianópolis, (Brasil). Doutor em Direito pela UFSC. Pós-Doutorado pela Universidade Federal de Pernambuco - UFPE, Recife. E-mail: rstersi@ hotmail.com
} 


\section{INTRODUÇÃO.}

A busca dos indivíduos pela satisfação das suas necessidades os fez parte de grupos sociais cada vez maiores até o surgimento das primeiras cidades-estados.

No desenvolvimento da Sociedade, o aumento da complexidade nas relações sociais produziram níveis cada vez maiores de cooperação e de conflito, de maneira a fazer com que os grupos sociais buscassem criar e aplicar instrumentos visando gerar a cooperação entre os seus integrantes bem como administrar os conflitos.

Para tanto criaram institutos como o Estado, a Religião, o Direito, que paradoxalmente atuam na construção da cooperação e na administração dos conflitos. Para Mitchell (1989, p. 01) a pesquisa do conflito humano implica também no estudo da sua ausência e, consequentemente, da cooperação.

A criação e o desenvolvimento dos Estados fez com que estes também passassem a se relacionar de maneira mais intensa por meio do comércio, das guerras, dos tratados entre outras, estabelecendo o que se designa por relações internacionais. Atualmente outros atores participam das relações internacionais tais como as Organizações Internacionais, as Empresas Transnacionais, entre outros. Assim, é num ambiente anárquico (sem a presença de um Estado ou Governo Mundial), que se manifestam os comportamentos de cooperação e de conflito dos atores internacionais estabelecendo o cotidiano das relações internacionais.

É justamente neste ambiente anárquico das relações internacionais que vão também ser criados e aplicados uma série de instrumentos que visam administrar as controvérsias surgidas entre os atores internacionais.

O objetivo do presente trabalho é apresentar de forma sucinta o fenômeno do conflito e de alguns dos principais instrumentos consensuais de administração do conflito nas relações internacionais. Dessa maneira a guerra e outras formas violentas de administração dos conflitos (designadas como autotutela) bem como os meios de decisões adjudicadas, como os tribunais internacionais e a arbitragem (heterocompositivos) não serão objeto de estudo.

A apresentação dos principais meios consensuais de administração pacífica dos conflitos e de suas características visa encontrar alguns padrões que permitam identificar a maneira pela qual tais instrumentos atuam na administração das controvérsias internacionais, restaurando a cooperação entre os agentes e permitindo o estabelecimento da paz. 


\section{2 - A COOPERAÇÃO E O CONFLITO NAS RELAÇÕES INTERNACIONAIS}

As relações internacionais não são um fenômeno moderno já que a organização da Sociedade em grupos politicamente organizados, dotados de certa complexidade, ocorreu há pelo menos seis mil anos, com a formação das primeiras cidades-estados na Mesopotâmia, no Egito e na Palestina. (COOK, 2005)

O desenvolvimento tecnológico e os instrumentos que permitiram uma maior coesão de certos grupos sociais fez surgir às primeiras grandes civilizações.

A sobrevivência, a segurança, o poder, o bem estar, a justiça, a ordem e a liberdade se constituem em alguns dos valores básicos que a Sociedade estabeleceu como pontos de convergência e, assim, buscou e busca criar os instrumentos necessários para alcança-los. Jackson e Sorensen (2007, p. 22) entendem que para realizar estes e outros valores a Sociedade criou a figura do Estado que é tido como instituição política e territorial, dotado de poderes necessários para orientar e satisfazer os referidos valores reconhecidos como fundamentais.

A criação progressiva de outros Estados fez com que ocorresse um incremento nas relações de cooperação e de conflito entre os mesmos.

Os Estados se relacionam dentro de determinados princípios entre os quais podem ser destacados o reconhecimento da soberania estatal; a inexistência de poder ou de autoridade superior a do Estado, de forma a caracterizar a existência de uma Sociedade anárquica nas relações internacionais.

Para Bull (2002) a relação entre os Estados se dá dentro de um sistema internacional caracterizado pela influência mútua (direta ou indireta). Dentro do sistema internacional surge a consciência da existência de certos valores e interesses comuns, decorrentes das relações mútuas, que geram um vínculo entre os Estados pautado pela aceitação de regras de conduta. A esse vínculo que destaca uma maior proximidade entre os Estados designa-se Sociedade Internacional.

Para Entelman (2005, p. 49), quando os agentes orientam e compreendem suas condutas de forma a permitir a realização dos objetivos programados, têm-se que as relações são de cooperação ou de coincidência. Em contrapartida, quando os agentes percebem que os objetivos são incompatíveis de serem realizados concomitantemente, têm-se as relações de conflito.

Segundo García (1975, p. 403): 
[...] denomina 'conflicto internacional' cualquier diferendo que se suscita entre dos o más Estados, por cuestiones de límites, por distinta interpretación de un tratado o laudo arbitral, por actos ilícitos cometidos por un Estado o sus nacionales contra otro Estado o sus nacionales, por violación de un tratado o de una convención internacional.

As relações internacionais de cooperação e de conflito existem desde a constituição das primeiras cidades-estados. Para Coulanges (2005, p. 154-158) a guerra, a paz, as alianças faziam parte das relações estabelecidas pelas cidades-estados, sendo esses atos garantidos pelos deuses locais. Assim como o conflito é tido como uma forma de relação à busca da paz e da cooperação também faz parte da mesma ideia.

Existe ainda, entretanto, uma grande dificuldade na identificação das fontes do conflito internacional. Para Gurr (1985, p. 405) "A despeito dos esforços de gigantes intelectuais do calibre de Kant, Spinoza, Rousseau e outros, pouco mais sabemos nós, hoje, sobre as fontes gerais de conflito internacional, do que sabia Tucídides há mais de dois milênios."

Diante dos conflitos, a Sociedade Internacional procura estruturar uma determinada ordem nas suas relações. Para Morgenthau (2003, p. 03-28) a Sociedade Internacional é caracterizada pela presença onipotente dos Estados que, agindo de forma centrada nos próprios interesses, buscam impor-se sobre os demais por meio do poder como forma de realização dos interesses nacionais. Assim, na perspectiva do autor, os Estados escolhem cooperar ou entrar em conflito a partir da estratégia que estabelecem como sendo a mais adequada para obter o máximo possível da satisfação dos próprios objetivos.

Ao referir-se à cooperação internacional, Deutsch (1982, p. 219-221) identifica que esta deve ser obtida mediante a redução dos interesses antagônicos e pelo fortalecimento dos interesses comuns.

Assim, de forma resumida é possível afirmar que os Estados, como os demais atores internacionais, orientam suas condutas para a realização dos seus objetivos (interesses nacionais), entre eles os aduzidos valores essenciais da segurança, da ordem, da liberdade, da justiça, da segurança e do bem-estar. Ao buscar realizar tais valores, cada ator deve adotar uma série de comportamentos que poderão ser percebidos pelos demais como manifestações de conflito ou de cooperação.

Por outro lado, na Sociedade Internacional, foi criada uma série de instrumentos que visam promover a administração dos conflitos internacionais como um meio de evitar a proliferação da violência e assegurar um mínimo de ordem e de segurança necessária para o 
desenvolvimento das relações internacionais. Um dos instrumentos principais para alcançar os referidos objetivos é o Direito Internacional.

De acordo com Bull (2002, p. 147), o direito internacional “[...] pode ser considerado como um conjunto de regras que ligam os Estados e os demais agentes da política mundial em suas relações recíprocas, aos quais se atribui status legal".

Bull (2002, p. 185) reconhece o papel importante do direito internacional na consecução da ordem internacional:

O direito internacional a que todos os estados do sistema internacional dão, de alguma forma, se assentimento formal ainda serve para executar suas funções tradicionais de identificar a ideia de uma sociedade de estados soberanos como o princípio operativo da política mundial, formulando regras básicas de coexistência e facilitando o cumprimento dessas e de outras regras.

Inicialmente os sistemas de resolução de conflitos internacionais só reconheciam os Estados como titulares do direito internacional. Mais recentemente também as Organizações Internacionais e os indivíduos foram reconhecidos como titulares de direitos e, portanto, como partes legítimas em certos sistemas de resolução de controvérsias internacionais.

As formas consensuais de administração de conflitos que são aplicadas no âmbito interno de um Estado (sistema de justiça) são similares às aplicadas nas relações internacionais, partindo dos mesmos princípios fundamentais. O elemento central de tais métodos é a manifestação da vontade dos interessados, buscando a formação de um consenso (acordo) no qual será possível a satisfação parcial ou total dos objetivos dos envolvidos.

\section{3 - MEIOS PACÍFICOS DE ADMINISTRAÇÃO DOS CONFLITOS INTERNACIONAIS}

É possível identificar diversas formas consensuais de gestão dos conflitos internacionais. É importante destacar que novas formas consensuais de administração de controvérsias continuam a ser criadas no âmbito internacional.

As formas de gestão consensual dos conflitos internacionais mais utilizadas hodiernamente são: a negociação diplomática; a conciliação; a mediação; os bons ofícios; o inquérito ou grupo de especialistas; as conferências ou congressos.

São características comuns dos meios consensuais: a) participação voluntária; b) manifestação da vontade; c) busca pela satisfação dos interesses; d) formação do consenso (acordo); e) poder decisório exclusivamente nas mãos dos interessados. 


\section{1 - Negociação Diplomática}

A negociação diplomática nada mais é do que a negociação direta dos atores internacionais que estão envolvidos no conflito. Na negociação diplomática os atores reconhecem os próprios interesses bem como os dos demais e buscam encontrar uma forma consensual de equacionar tais interesses por meio de um acordo. ${ }^{2}$

Em caso de conflito entre Estados, cada agente estará representado por seus plenipotenciários (diplomatas) que devem procurar, por meio de um esforço colaborativo, formas de compor o conflito.

As negociações diplomáticas são, sem qualquer dúvida, a maneira mais comum de administração dos conflitos nas relações internacionais.

A negociação tanto pode ser realizada dentro de um contexto colaborativo entre os agentes como dentro de um contexto adversarial, onde cada agente visa impor a sua posição em relação aos demais. Tal fato ocorre nas situações em que os Estados se prendem as suas posições e não aos seus interesses. Quando a negociação se restringe as posições, a sua característica central passa a ser o poder que cada parte detém para conseguir impor sua vontade sobre os demais, gerando um embate entre os agentes dentro do procedimento.

A diferença entre um contexto colaborativo e um contexto adversarial parece ter ocorrido nas negociações entre Egito e Israel sobre a península do Sinai, após a ocupação por Israel em 1967, na guerra dos Seis Dias. Enquanto cada parte se refugiava nas suas posições ${ }^{3}$ não houve a possibilidade de acordo.

Somente quando as partes buscaram a composição por meio dos interesses é que foi possível um acordo diplomático sobre a questão. ${ }^{4}$

Atualmente o mesmo problema se apresenta no conflito entre Israel e Síria sobre os territórios das Colinas de Golam; entre Israel e Palestina, no que diz respeito às fronteiras de cada Estado e numa série de outros conflitos internacionais.

\footnotetext{
${ }^{2}$ Fisher \& Ury \& Patton, 205, p. 58-62; Andrade \& Alyrio \& Macedo, 2004, p. 12; Martinelli \& Ventura \& Machado, 2004, p. 37-39; Gómez \& López, 2007, p. 51-53.

${ }^{3}$ A posição do Egito era sobre a necessidade de devolução por se tratar território egípcio invadido por Israel, sem apresentar qualquer contrapartida. A posição de Israel era pela impossibilidade da devolução já que o Egito era inimigo de Israel, ameaçando a existência do território judaico ao colaborar com outros estados que visavam a destruição de Israel.

${ }^{4}$ Os interesses do Egito de ter o território devolvido a sua soberania foram combinados com os interesses de Israel pela segurança do seu território mediante um acordo de paz (Camp David) onde se ratificou o reconhecimento do estado de Israel pelo Egito e a criação de uma zona desmilitarizada no Sinai, nas proximidades da fronteira de Israel, que garantissem a segurança do estado judaico.
} 
A negociação dentro de um contexto adversarial também pode gerar acordos. Entretanto tais acordos tem uma tendência maior ao descumprimento no futuro, diante da utilização de elementos de coerção (poder) para impor a vontade de um agente sobre os demais. ${ }^{5}$

As principais vantagens na utilização das negociações diplomáticas na gestão das controvérsias internacionais são: a possibilidade de interpretação direta pelos agentes do Direito Internacional; a disponibilidade do procedimento, já que nenhuma das partes é obrigada a participar do procedimento de negociação ou a realizar qualquer acordo; a informalidade do procedimento, pois não existem regras rígidas para o desenvolvimento do procedimento, cabendo aos próprios interessados organizar esse procedimento; a possibilidade de manter o poder de decisão nas mãos dos próprios interessados, sem delegá-lo a terceiros.

Caso as negociações diplomáticas sejam bem sucedidas o seu resultado mais comum é a realização de um acordo internacional que vai versar sobre a totalidade ou parte do objeto do conflito. $\mathrm{O}$ acordo internacional pode representar:

a) Estabelecimento de concessões recíprocas (transação), ainda que não se exija proporcionalidade das concessões, e que satisfaça, ainda que parcialmente, as expectativas e valores das partes em conflito. Exemplo: tratado entre Israel e Egito sobre a península do Sinai, tratado de Petrópolis entre Brasil e Bolívia sobre a questão do Acre;

b) Desistência por um ou mais agentes dos próprios interesses inicialmente apresentados, em razão da conveniência ou do interesse do agente em se ver livre do problema sendo que, nessa hipótese, uma das partes abandona o conflito e opta por cessar a conduta de resistência, permitindo que a outra parte alcance os objetivos. Na desistência, o agente desistente deixa de aplicar qualquer recurso que lhe permita alcançar os seus objetivos iniciais. Um exemplo de desistência é o tratado de paz entre Rússia e Alemanha, assinado em Brest-Litowsky em 1918, que retirou a Rússia da $1^{\text {a }}$ Guerra Mundial. O interesse central do governo russo de vencer os alemães e manter a integralidade do território russo foi substituído pela necessidade de consolidação dos ideais políticos da revolução bolchevique, ocorrida pouco antes, deixando de lado os acordos militares celebrados com os países da Entente. Dessa forma o governo russo desistiu dos

\footnotetext{
${ }^{5}$ É o que ocorreu com os termos da negociação que gerou o Tratado de Versalhes (impôs a paz a Alemanha ao final da I Guerra Mundial). Paulatinamente os termos do Tratado passaram a ser desrespeitados pela Alemanha (ocupação da zona desmilitarizada do Sarre, rearmamento da Alemanha, união com a Austria etc)
} 
territórios russos que eram reclamados pela Alemanha e aceitou as imposições apresentadas;

c) Submissão do Estado, quando esse se submete ao outro ao reconhecer e adotar os valores dos adversários como próprios e, por vezes, reconhecendo-lhe a titularidade de um Direito Internacional;

d) Imposição da vontade de um Estado sobre o outro, quando apenas uma das partes alcança as suas metas enquanto o outro vê frustrados os seus objetivos. Na imposição um ator mais poderoso, por meio do seu comportamento e de suas ações de poder, obriga o adversário a cessar o seu comportamento de resistência de forma a alcançar a satisfação integral dos seus objetivos.

Realizado o acordo espera-se, a partir daí, o cumprimento voluntário das obrigações assumidas, sob pena de responsabilização internacional do ator que venha violar as obrigações assumidas no acordo.

As negociações diplomáticas foram, ao longo da história, em regra sigilosas, principalmente quando visavam o estabelecimento de pactos secretos ou alianças militares. Atualmente existe um esforço, principalmente no âmbito das Organizações Internacionais, para que as negociações sejam pautadas pela transparência, como um meio de evitar que seja utilizada para burlar o Direito Internacional.

Conforme Mello (1982, p. 94) um dos primeiros tratados internacionais conhecidos, celebrado por volta de 1278 A.C., em que egípcios e hititas celebraram a paz entre os dois reinos após diversas guerras, foi obtido mediante negociação diplomática entre as partes. Para Conrad (1979, p.157) entre as matérias estabelecidas no tratado encontrava-se a celebração de um pacto de não agressão e de defesa mútua (diante das preocupações das duas partes do fortalecimento de poder militar de um terceiro: Assíria); a previsão da extradição dos inimigos políticos de cada estado; o respeito dos governantes egípcios à lei de sucessão no Hatti (país dos hititas). O cumprimento do tratado era garantido pelas divindades dos dois povos.

Os atores internacionais utilizam as negociações diplomáticas por se tratar de uma forma de resolução de conflitos sobre as quais os próprios interessados possuem total controle sobre o procedimento. Os agentes participam da negociação enquanto julgarem conveniente fazê-lo, podendo abandonar o procedimento quando desejarem.

Por outro lado, em certas Organizações Internacionais a negociação diplomática é apenas umas das etapas do sistema próprio de administração de controvérsias. Caso as partes não cheguem a um acordo, as questões discutidas ao longo da negociação vinculam a matéria 
que poderá ser apresentada e discutida nas demais etapas, inclusive numa eventual etapa jurisdicional (arbitragem ou tribunal internacional), proibindo-se aos agentes inovarem quanto a questão conflituosa a ser resolvida. ${ }^{6}$

O acordo celebrado entre as partes por meio das negociações diplomáticas só deveriam produzir, em regra, efeitos jurídicos para as mesmas, não sendo oponível perante terceiros. ${ }^{7}$

No âmbito das Organizações Internacionais de Integração, entretanto, certos direitos reconhecidos a um dos Estados, por meio de uma negociação diplomática, devem ser automaticamente estendido aos demais integrantes da organização. Trata-se da cláusula de nação mais favorecida.

Conforme Aréchaga (1980, p. 176-177), no âmbito da Organização das Nações Unidas (ONU) as negociações diplomáticas e os demais métodos pacíficos de resolução de conflitos estão no mesmo plano (artigo 33, capítulo VI, da Carta da ONU), apesar da proposta da Tchecoslováquia, na década de setenta, em reconhecer uma posição predominante da negociação em relação aos demais meios bem como dar-lhe um caráter de obrigatoriedade.

\section{2 - Conciliação}

Para Merrills (2011, p. 62) como Mello (1982, p. 937) a conciliação está associada a um órgão dotado de regras e de procedimento para intermediar a resolução dos conflitos entre as partes.

O conciliador é escolhido pelas partes ou indicados pelo órgão de conciliação e deverá colaborar para que as partes resolvam o conflito.

Pazartzis (1992, p. 71-72) aponta que a conciliação se caracteriza por uma negociação intermediada por um órgão institucional (ad hoc ou permanente).

Uma das características importantes da conciliação como dos demais métodos consensuais é que o (terceiro) conciliador não tem poder de decidir a demanda de maneira vinculativa. $\mathrm{O}$ poder de decidir remanesce com as partes. Ao mesmo tempo o conciliador deve ser imparcial, atuando no procedimento de forma a dar tratamento igualitário para as partes.

\footnotetext{
${ }^{6}$ É o caso, por exemplo, do sistema de solução de controvérsias do Mercosul e da Organização Mundial do Comércio e do procedimento por descumprimento julgado pelo Tribunal de Justiça da União Europeia.

${ }^{7}$ Apesar de existir exceções como no caso da Conferência de Munique, em 1938, em que França, Inglaterra, Alemanha e Itália decidiram pela autorização de incorporação pela Alemanha da região dos Sudetos, pertencente à Tchecoslováquia. A Tchecoslováquia não participou da Conferência e não fazia parte do acordo.
} 
Em alguns tratados internacionais o órgão de conciliação poderá apresentar, ao final do procedimento, suas impressões sobre o conflito (na forma de parecer ou relatório) expondo os aspectos fáticos e jurídicos que reputar importantes do conflito e sugerindo alternativas para a sua resolução. As partes não estão obrigadas a aceitar as sugestões do conciliador. ${ }^{8}$

Para Pazartzis (1992, p. 106-109) a conciliação por vezes é considerada uma etapa intermediária entre as negociações diplomáticas e as formas jurisdicionais.

A comissão de conciliação tem o dever de procurar colaborar para que as partes resolvam suas diferenças quer restabelecendo a comunicação entre as mesmas, quer intermediando propostas lançadas de parte a parte. O conciliador, ainda que possua a nacionalidade de uma das partes em conflito, não age como defensor dos interesses do estado e sim como terceiro neutro que colabora para ajudar as partes a encontrar um meio de colocar fim ao conflito. Sua participação é a de um facilitador que necessita ganhar a confiança das partes em conflito para poder atuar.

$\mathrm{Na}$ conciliação as partes possuem, como na negociação, a autonomia da vontade e a disponibilidade quanto ao procedimento. Não podem ser obrigadas a resolver o conflito por meio do acordo e só participam do procedimento enquanto reputarem importante a sua participação e acreditarem na possibilidade da resolução do conflito com a ajuda da comissão de conciliação.

Certos tratados internacionais estabelecem a obrigatoriedade dos estados se submeterem a uma etapa de conciliação para a resolução de conflitos. ${ }^{9}$ A ideia da obrigatoriedade do estabelecimento de uma etapa de conciliação não condiz com a característica da autonomia da vontade dos agentes e da disponibilidade do procedimento de conciliação. Se os agentes só participam da conciliação se assim desejarem não há sentido obrigá-los a instaurar um procedimento de conciliação quando já tomaram a decisão de buscar uma outra alternativa para administrar o conflito.

Outra característica importante da conciliação é a celeridade visto que o procedimento de conciliação tende a ser mais informal e rápido do que os procedimentos jurisdicionais. Todas as questões debatidas e eventuais provas produzidas num procedimento de conciliação servem

\footnotetext{
${ }^{8}$ É o caso do Protocolo de Olivos, no Mercosul, que prevê, de forma facultativa, que as partes podem submeter as controvérsias, após as negociações diretas, ao Grupo Mercado Comum que, ao final, apresentará parecer sobre o assunto.

${ }^{9}$ Nesse sentido têm-se o Protocolo de Brasília, no Mercosul, que previa a obrigatoriedade da etapa de conciliação perante o Grupo Mercado Comum, caso as negociações diretas entre os estados partes houvessem fracassado.
} 
para o convencimento das partes (e não do conciliador) visando colaborar para que as mesmas alcancem um acordo.

Anteriormente poder-se-ia indicar o sigilo como outra característica da conciliação. Ocorre que atualmente os trabalhos das comissões de conciliação são, em regra, pautados pela transparência e, em caso de acordo, este acaba se materializando num acordo internacional, de conhecimento público, visto que no moderno direito internacional não se admitem mais os tratados com cláusulas secretas.

\section{3 - Mediação}

A idéia de mediação está muito próxima da conciliação e dos bons ofícios. A mediação é uma forma de resolução de conflitos em que uma ou mais autoridades (mediador) é escolhida pelos interessados para atuar como facilitador do processo de comunicação, aproximando as partes para que as mesmas possam solucionar suas diferenças.

García (1975, p. 405-406) aponta que a mediação:

Consiste en someter la controversia a uno o más gobiernos o a uno o más ciudadanos eminentes de cualquier Estado extraño a los que hallan en litigio, para asistir a las partes en el arreglo de la controversia de la manera más sencilla y directa, evitando formalidades y procurando hallar una solución aceptable.

Como na conciliação, o mediador não tem poder de decidir de forma vinculativa (obrigatória) o conflito. O poder de decisão continua pertencendo as partes.

O mediador atua como um facilitador, ouvindo as pretensões das partes, buscando os fatos, intermediando conversas e propondo alternativas para compor o litígio. Difere da conciliação onde o terceiro é um órgão, com características institucionais.

Na mediação o terceiro é normalmente um chefe de estado ou de governo ou uma alta autoridade governamental (ministros). Na mediação internacional, caso haja mudança da pessoa que exercia o cargo, designado como mediador (em razão de eleições ocorridas que promoveram a mudança do chefe de estado ou do chefe de governo, por exemplo) o novo titular do cargo, em regra, segue na atuação como mediador.

Têm-se, assim, que o mediador pode não ser uma determinada pessoa física e sim o ocupante de uma determinada autoridade (é o caso quando se designa o Papa ou o Secretário 
Geral das Nações Unidas como mediador, não importando quem seja o indivíduo que ocupe a função)

Ao servir como mediador o terceiro deve atuar com neutralidade e imparcialidade, buscando a equidistância das partes e deixando de emitir juízos de valores a respeito do conflito. Ao mesmo tempo, deve procurar conhecer o conflito e estabelecer uma relação de confiança com os interesssados.

Também na mediação é estabelecido um procedimento para o desenvolvimento dos atos necessários a busca de um compromisso entre as partes.

As partes possuem a disponibilidade do procedimento, não estando obrigadas a chegar a qualquer acordo para colocar fim as controvérsias.

O mediador buscará fazer com que as partes resolvam o conflito em sua plenitude e que o acordo alcançado seja o mais satisfatório possível para os interessados, diminuindo a possibilidade de posteriores descumprimentos. Caso não seja possível um acordo sobre a totalidade do conflito o mediador deverá buscar que as partes alcançem pelo menos um compromisso parcial ou, eventualmente, a escolha de outro método pacífico de administração dos conflitos.

Também na mediação é possível a realização de provas sendo importante destacar que o destinatário das provas, como na conciliação, não é o mediador (que não julga) e sim as próprias partes em conflito. As provas poderão servir como elementos de modificação ou revisão da conduta das partes em relação ao conflito. Com a realização de uma determinada prova uma das partes em conflito pode se convencer que a outra parte tem razão; que não possui qualquer direito que possa embasar suas pretensões etc.

Ao final do procedimento de mediação internacional, assim como na conciliação, o mediador, se assim desejar, poderia apresentar o seu próprio ponto de vista sobre o conflito, apontando os comportamentos desejáveis para que as partes coloquem fim as suas pendências. Trata-se de parecer (ou relatório) não vinculativo já tem caráter de mera recomendação.

Alguns exemplos de mediação internacional são: a interferência da Santa Sé por meio do Papa João Paulo II para a celebração do acordo entre Chile e Argentina, em 1978, no que concerne a linha fronteiriça entre os dois países no canal de Beagles; a atuação dos Presidentes de Brasil, Argentina, Chile e Estados Unidos e do Secretário Geral da OEA ${ }^{10}$ no acordo que colocou fim ao conflito fronteiriço entre o Equador e o Peru na Serra do Condor.

\footnotetext{
${ }^{10}$ Organização do Estados Americanos.
} 


\section{4 - Bons Ofícios}

Difícil tarefa é estabelecer os elementos diferenciadores entre mediação e bons ofícios. Mello (1982, p. 934) explica que a distinção prática entre mediação é bons ofícios não é fácil, de modo que os institutos são confundidos.

Também Strenger (1998, p. 91) tem dificuldades em estabelecer os elementos que diferenciam os bons ofícios da mediação:

A mediação vai mais longe do que os bons ofícios: o terceiro mediador participa das negociações, as dirige, fornece propostas concretas de solução e se esforça por conciliar as pretensões opostas e apaziguar os ânimos.

Para Soares (1999, p. 23), nos bons ofícios a intervenção do terceiro tanto pode partir de sua própria iniciativa, devendo ser aceita pelas partes para que haja legitimação, ou é solicitada pelas partes em conflito, com o intuito de evitar o aumento da escalada conflituosa e preparar a possibilidade de utilização de outros métodos pacíficos (jurisdicionais ou não) de resolução do conflito.

Nos bons ofícios a participação do terceiro (seja um estado, seja um particular) estaria atrelada aos meios necessários para que as partes em conflito estabeleçam ou restabeleçam um canal de negociação.

Se na mediação o terceiro participa ouvindo as pretensões das partes; algumas vezes esclarecendo-as quanto a eventuais dúvidas, ou sugerindo maneiras como as partes poderiam por fim as suas pendências, nos bons ofícios a participação do terceiro não é tão ativa.

O terceiro, nos bons ofícios, coloca a disposição das partes território neutro para que as mesmas possam restabelecer a comunicação; organiza uma pauta de discussões colocando, a disposição das partes, os meios necessários para que as mesmas continuem o diálogo.

Nos bons ofícios o terceiro não sugere propostas para pôr fim ao conflito, mas colabora para a manutenção ou o restabelecimento da comunicação entre as partes, buscando que as mesmas cheguem a um meio de resolver suas controvérsias.

\section{5 - Conferências e Congressos}

As Conferências e os Congressos foram meios consensuais de administração de controvérsias internacionais muito utilizados a partir do XIX. 
As conferências e os congressos são negociações diretas de caráter multilateral. São diversas partes interessadas que negociam entre si buscando uma forma de resolver as controvérsias. Pode-se até incluir as conferências como uma das espécies de negociações diretas multipartes.

As conferências atualmente são públicas havendo, portanto, a influência da opinião pública assim como a possibilidade de intervenção de outros atores das relações internacionais (como as $\mathrm{ONGs}^{11}$ e as Organização Internacionais). Por vezes possuem um objeto amplo e um número elevado de participantes, o que dificulta o estabelecimento e a combinação de interesses comuns e a delimitação dos seus objetivos.

Mello (1982, p. 932) apresenta algumas desvantagens das conferências de chefes de Estado: a) entra em jogo, muitas vezes, a animosidade pessoal entre os chefes de Estado; b) as reuniões nem sempre têm um objeto preciso; c) os especialistas são afastados.

Tais críticas apresentadas por Mello podem ser reconhecidas nas grandes conferências de paz, como a conferência de Paris. MacMillan (2004) aponta a animosidade pessoal que existia entre os principais líderes vencedores da I Guerra Mundial e a dificuldade de tais líderes decidirem com base em princípios anteriormente aceitos. Apesar da conferência de Paris utilizar especialistas, muitas vezes a opinião dos especialistas era desconsiderada em prol do interesse político das potências vencedoras.

Por outro lado o que se verifica nas conferências é que os conflitos tendem a ser resolvidos dentro de um quadro de bipolaridade, ainda que sejam múltiplos os atores.

Para Entelman (2005, p. 85-87) as alianças são formadas, em tal situação, levando em conta as escolhas de objetivos que contemplem os valores essenciais de diversos estados, permitindo o seu agrupamento e a sua apresentação como uma das partes dentro de um contexto bipolar. Logo cada parte é constituída, nessas situações, de diversos agentes agrupados, em aliança, a partir de temas que simbolizam os seus interesses centrais e que lhes permita maximizar a possibilidade de satisfação de tais interesses mediante, inclusive, a junção dos instrumentos de poder necessários para promover a modificação do comportamento da outra parte.

Um exemplo de tal situação seria o embate entre os países desenvolvidos (Estados Unidos e União Europeia) com os países em desenvolvimento sobre a questão dos subsídios agrícolas na rodada de Doha, da $\mathrm{OMC}^{12}$.

\footnotetext{
${ }^{11}$ Organizações não governamentais.

12 Organização Mundial do Comércio.
} 
Algumas das principais conferência ou congressos foram:

a) Congresso de Viena em 1815: restaurou o mapa da Europa e alterou a distribuição das colônias, principalmente nas Américas, após a derrocada do Império de Napoleão Bonaparte. Conforme Kissinger (2007, p.65-86) a tônica do congresso de Viena foi o estabelecimento de um sistema de equilíbrio de poder, designado concerto europeu, que permitiu um longo período sem guerras na Europa (até a eclosão da I Guerra Mundial). Para Nye Jr (2009, p.83) o equilíbrio de poder na Europa sofreu alterações a partir de 1870 que levaram o sistema ao desencadeamento da I Guerra Mundial.

b) Congresso de Berlim em 1885: organizado por Bismarck, visava regulamentar a distribuição das áreas coloniais na África e Ásia. Entre os seus resultados está o reconhecimento da influência das grandes potências européias em determinadas áreas da África e da Ásia. Também colocou fim as esperanças de Portugal em ver reconhecido o seu direito de ligação territorial entre as suas colônias em Angola e Moçambique, já que o território de ligação foi colocado sob o controle britânico;

c) Conferência da Argélia em 1906: tratou mais uma vez da redistribuição, pelas potências européias, das colônias na Ásia e África, permitindo que a Alemanha obtivesse novos territórios coloniais;

d) Conferência de Paris em 1919 que colocou fim a I Guerra Mundial. Como decorrência da Conferência de Paris foram celebrados tratados entre os países vencedores da Guerra e os países derrotados (Bulgária, Áustria, Hungria, Alemanha e Turquia) que reconheceram novos estados independentes (Polônia, Tchecoslovaquia, Iuguslávia, Lituânia, Letônia, Estônia, Finlândia etc) surgidos da fragmentação de territórios dos estados derrotados e da Russia, bem como foram distribuídos territórios e colônais dos países vencidos para os países vencedores. (MacMillan, 2004; NICOLSON, 2014; BECKER, 2011)

e) Conferência de Munique em 1938: buscava impedir a eclosão da guerra na Europa (acabou apenas adiando o início da II Guerra Mundial) ao negociar os direitos da Alemanha sobre a região dos Sudetos (que pertencia a Tchecoslováquia) e da Itália em possuir um império africano (buscando a legalização da ocupação da Abissínia). Curiosamente a Tchecoslováquia, que era uma das partes em conflito, não foi convidada para participar.

Atualmente são inúmeras as conferências internacionais sobre os mais diversos temas, tais como: clima e emissão de gazes na atmosfera; ocupação da Antártida; exploração e 
ocupação do espaço sideral; exploração e ocupação dos mares e oceanos; facilitação do comércio internacional etc.

\section{6 - Inquéritos e Procedimentos Investigatórios}

Também chamados de comissões de investigação é uma forma de resolução de conflitos em que as partes submetem o litígio a uma comissão de peritos que irá investigar os fatos e, ao final, apresentar um relatório não vinculante (obrigatório).

Nos inquéritos os fatos são buscados por peritos-investigadores inclusive nos casos que envolvam questões técnicas a serem esclarecidas.

Para Mello (1982, p. 937) este sistema apresenta as seguintes características: a) visa a apurar meramente fatos; b) o relatório não é obrigatório.

Fenwick (1963, p. 581), comentando o texto da Convenção de Haia de 1899 e 1907, informa a respeito das características do inquérito:

Se tomaron también medidas para que, dado que el informe debía limitarse a una comprobación de hechos, no se le atribuyera en ningún momento el carácter de una dicisión arbitral, quedando las partes en entera libertad para decidir com respecto al destino que deseaban dar al resultado de la investigación.

Os investigadores poderão ser indicados pelas partes ou por uma Organização Internacional. Deverão, entretanto, exercer as suas funções com imparcialidade e independência em relação às partes. Divergindo dessa característica, Soares (1999, p. 24) entende que a imparcialidade e a independência são dispensáveis para a análise de questões fatuais que depois estarão submetidas ao crivo de outras esferas de decisão.

As investigações são realizadas sem o princípio do contraditório visto que o relatório final é meramente informativo para as partes, esclarecendo-as sobre questões fáticas e seus aspectos técnicos.

É uma forma de gestão de conflitos visto que uma das partes, após a apresentação do relatório final pode estar convencida que a outra parte tenha razão; que não deseja fazer valer o seu direito; ou mesmo que deve fazer concessões para por fim a controvérsia.

García (1975, p. 406), ao comentar as comissões de investigação instituídas pela convenção de Haia de 1899, informa que as mesmas tinham:

[...] el objeto de conocer y hacer conocer la verdad sobre las causas de un incidente internacional y de esse modo ganar tiempo para que se seransen los espíritus y para que los conflictos perdieran el carácter virulento del principio, particularmente en las 
cuestiones de límites, en la opinión pública de los respectivos Estados suele ser inflamada artificialmente por agentes pagados ex profeso, que irritan y exacerban los sentimientos nacionalistas.

O inquérito muitas vezes não faz com que as partes resolvam o litígio imediatamente mas, por vezes, serve para estimulá-las a utilizar outras formas pacíficas que busquem equacionar suas pendências.

É importante destacar que a investigação realizada no inquérito não se reveste das características das provas produzidas e destinadas a um julgador. $\mathrm{O}$ destinatário do parecer produzido numa comissão de inquérito são os Estados litigantes, buscando convencê-los da materialidade dos fatos e esclarecê-los nos casos de dúvidas técnicas.

O relatório final informa as partes em conflito como os especialistas vislumbram o litígio apresentando o resultado das investigações. Caso os litigantes estejam convencidos da adequação do relatório final espera-se que fiquem mais propensos a resolver suas controvérsias por meio de outras formas pacíficas de gestão de conflitos.

\section{4 - CONSIDERAÇÕES FINAIS}

As relações internacionais são caracterizadas pela existência de uma dinâmica entre o conflito e a cooperação entre os seus atores, sendo o Estado o seu principal agente.

A dinâmica do conflito e da cooperação existe para que os atores busquem satisfazer o máximo possível dos seus interesses, pouco importando se são políticos, econômicos, sociais etc. Não é incomum que dados atores estejam em relações de conflito e de cooperação ao mesmo tempo.

Atualmente, por exemplo, o governo brasileiro e o dos países designados bolivarianos ${ }^{13}$ se encontram em disputas diplomáticas decorrentes do impedimento da antiga presidenta do Brasil Dilma Roussef e da sua substituição pelo governo de Michel Temer. Ao mesmo tempo em que conflitam no campo diplomático (pelo reconhecimento ou não do governo Temer) continuam cooperando nas relações comerciais, por exemplo.

A utilização dos meios consensuais de administração de controvérsias nas relações internacionais visa, assim, buscar fazer cessar os conflitos existentes permitindo que uma ou todas as partes envolvidas possam alcançar a realização dos seus interesses juridicamente protegidos pelo Direito Internacional.

${ }^{13}$ Bolívia, Equador e Venezuela. 
As vantagens na utilização das formas consensuais de resolução de conflitos se revela no que diz respeito à pacificação mais duradoura e efetiva das relações internacionais, criandose um ambiente mais propício à confiança e, consequentemente, a proliferação das relações de cooperação entre seus agentes.

Com a limitação ao emprego da violência, diminui-se a possibilidade dos atores continuarem tomando suas relações com os demais como uma relação entre adversários (que devem ser derrotados), permitindo o fortalecimento da ideia central de que as relações internacionais atuais devem ser pautadas, em regra, por comportamentos de colaboração, sendo possível divergir e continuar colaborando ao mesmo tempo, estimulando o estabelecimento de uma cultura voltada ao consenso.

Outra característica reconhecida como comum a todos os métodos pacíficos de gestão de controvérsias é a possibilidade de o conflito ser solucionado com base em regras procedimentais e de mérito previamente estabelecidas e aceitas pelos atores (aplicação do Direito Internacional).

Também se reconhece que os atores internacionais optam precipuamente pela utilização de meios consensuais de administração dos conflitos. Por meio de tais métodos é possível que os interessados tenham controle sobre o resultado, diminuindo a possibilidade de decisões que sejam contrárias aos seus interesses.

O uso de meios heterocompositivos de administração de conflitos, tais como a arbitragem e os tribunais internacionais (decisão adjudicada), é utilizado como recurso último nas relações internacionais e ocorre apenas nas hipóteses em que não seja possível a construção de uma decisão consensual pelas partes envolvidas na disputa.

\section{REFERÊNCIAS BIBLIOGRÁFICAS}

ANDRADE; Rui Otávio Bernardes de; ALYRIO, Rovigati Danilo; MACEDO, Marcelo Alvaro da Silva. Princípios de negociação. São Paulo: Atlas, 2004.

ARÉCHAGA, Eduardo Jiménez de. El derecho internacional contemporaneo. Madrid: Tecnos, 1980.

BECKER, Jean-Jacques. O tratado de Versalhes. São Paulo: Editora Unesp, 2011. 
BULL, Hedley. A sociedade anárquica. Brasília: UNB e Instituto de pesquisa de relações internacionais e São Paulo: Imprensa Oficial do Estado, 2002.

BURDEAU, Georges. O estado. São Paulo: Martins Fontes, 2005.

CASELA, Paulo Borba. Arbitragem - lei brasileira e praxe internacional. São Paulo: LTR, $2^{\text {a }}$ ed., 1999.

CERVO, Amado Luiz. BUENO, Clodoaldo. História da política exterior do Brasil. $\quad$ São Paulo: Ática, 1992.

CONRAD, Philippe. Os hititas e as civilizações anatolianas. Rio de Janeiro: Otto Pierre Editores, 1979.

COOK, Michael. Uma breve história do homem. Rio de Janeiro: Jorge Zahar Editor, 2005.

COULANGES, Fustel de. A cidade antiga. São Paulo: Rideel, 2005.

DEUTSCH, Karl. Análise das relações internacionais. 2a ed., Brasília: UNB, 1982.

ENTELMAN, Remo F. Teoria de conflictos. Barcelona: Gedisa, 2005.

FENWICK, Charles G. Derecho Internacional. Buenos Aires: Bibliográfica Omeba, 1963.

FISHER, Roger; URY, William; PATTON, Bruce. Como chegar ao sim. $2^{\text {a }}$ ed., São Paulo: Imago, 2005.

GURR, Ted Robert. Manual do conflito político. Brasília: UNB, 1985. 552 p.

GARCÍA, Eduardo Augusto. Manual de derecho internacional público. Buenos Aires: Depalma, 1975 
GÓMEZ, Francisco Javier Gorjón; LÓPEZ, Karla Annett Cynthia Sáenz. Métodos alternos de solución de controvérsias. México : Cecsa, 2007.

HOBBES, Thomas. Leviatã. São Paulo: Abril Cultural, 1974.

JACKSON, Robert; SORENSEN, Georg. Introdução às relações internacionais. São Paulo: Zahar, 2007.

KISSINGER, Henry. Diplomacia. Lisboa: Editora Gradiva, 2007.

MACMILLAN, Margaret. Paz em Paris. Rio de Janeiro: Editora Nova Fronteira, 2004.

MARTINELLI, Dante P.; VENTURA, Carla A. A.; MACHADO, Juliano R. Negociação internacional. São Paulo: Atlas, 2004.

MELLO, Celso Duvivier de Albuquerque. Curso de direito internacional público. Rio de Janeiro: Freitas Bastos, v.2, 1982.

MERRILLS, J. G. International dispute settlement. Cambridge: University Press, 2011.

MITCHELL, Christopher Roger. The structure of international conflict. N. York: St. Martin's Press, 1989.

MORGENTHAU, Hans J. A política entre as nações. Brasília: UNB e Instituto de pesquisa de relações internacionais e São Paulo: Imprensa Oficial do Estado, 2003.

NICOLSON, Harold. O tratado de Versalhes. São Paulo: Globo Livros, 2014.

NYE JR, Joseph S. Cooperação e conflito nas relações internacionais. São Paulo: Editora Gente, 2009. 
SOARES, Guido F. S. Órgãos das soluções extrajudiciárias de litígios. São Paulo: RT, 1985. Solução e prevenção de litígios internacionais: tipologia e características atuais. In MERCADANTE, Araminta de Azevedo; MAGALHÃES, José Carlos de (Coordenadores). Solução e prevenção de litígios internacionais. Porto Alegre: Livraria do Advogado e Necin Projeto Capes, volume II, 1999.

STRENGER, Irineu. Relações Internacionais. São Paulo: LTR, 1998.

VIANA, Hélio. História da República. $2^{\text {a }}$ Ed, São Paulo : Melhoramentos, 1962. 